\title{
Twenty-Nail Dystrophy Treated with Hydroxychloroquine in a Patient with Alopecia Areata
}

\author{
Soo Hyeon Bae, Seok Hwan Jang, Young Ho Won \\ Department of Dermatology, Chonnam National University Medical School, Gwangju, Korea
}

Dear Editor:

Twenty-nail dystrophy (TND) is not rare in patients presenting with alopecia areata (AA); however, to date, no universally accepted treatment strategy has been established for TND ${ }^{1}$. We present a patient with TND treated with hydroxychloroquine. We received the patient's consent form about publishing all photographic materials.

A 49-year-old female patient presented with nail fragility and patchy hair loss, which both started a year ago. Prior to visiting Chonnam National University Hospital, the patient reported receiving systemic antifungal and topical corticosteroid drugs for the nails without improvement. Her scalp showed patches of hair loss (Fig. 1A). Her nails showed ridging, lack of luster and brownish discoloration (Fig. 1B, D). Potassium hydroxide preparation $(\mathrm{KOH})$ and fungal cultures of the nail specimens showed negative results. Histopathological examination of the nail matrix revealed hyperkeratosis, acanthosis, mild spongiosis, epidermal lymphoid cells infiltrates and vacuolar degeneration of the basal keratinocytes (Fig. 2). On medical history, she has been treated with diabetes mellitus for 6 years. Routine blood tests were normal and no other cutaneous disorder was detected. The patient was treated with intralesional injections of trimacinolone acetonide for $\mathrm{AA}$ and hydroxychloroquine $(200 \mathrm{mg} / \mathrm{d})$ for TND. AA improved after 4 months whereas TND improved after a year (Fig. 1C, E). Notably, discontinuation of hydroxychloroquine administration led to the recurrence of TND after 6 months, which however showed resolution following re-treatment with hydroxychloroquine for 20 months without recurrence and drug-induced adverse events. TND or trachyonychia is characterized by diffuse ridging, lack of luster, and a sandpaper-like roughening of the nail surface. TND could be an idiopathic condition or a manifestation of disorders including AA, psoriasis, and lichen planus $^{2}$. Kasumagic-Halilovic and Prohic ${ }^{1}$ proposed that because of the similarity in structure and growth patterns between hair follicles and nails, these appendages are common targets for inflammatory cells in AA. The histopathological feature also suggests the possibility of coincident lichen planus in our case ${ }^{2}$. Treatment options for TND include systemic treatment with oral prednisone and griseofulvin, psoralen ultraviolet $\mathrm{A}$, topical steroids and retinoids, and/or steroid injections.

In our case, hydroxychloroquine induced remission of TND, which was nonresponsive to topical steroid treatment. Systemic steroid was not priorly considered because of high blood sugar. The mechanism of antimalarials in dermatologic disorders includes interfering antigen presentation by major histocompatibility complex molecules ${ }^{3}$. They also reduce activity levels of inflammatory cytokines such as interleukin (IL)-1, IL-2, IL-5, and IL-6. Additionally, antimalarials modulate the innate immune system by inhibiting toll-like receptor (TLR)-9 signaling. Interestingly, $\mathrm{AA}$ is an autoimmune disease mediated by autoreactive CD8 + T-cells, which recognize hair follicles and nails as antigens ${ }^{1}$. Moreover, IL-2 is a well-known driver of CD8 + T-cells in AA, and the expression of TLR-9 in mononuclear cells in the peripheral blood is significantly up-regulated in patients with $\mathrm{AA}^{4,5}$. We speculate that the admin-

Received February 19, 2018, Revised July 1, 2018, Accepted for publication July 11, 2018

Corresponding author: Young Ho Won, Department of Dermatology, Chonnam National University Hospital, 42 Jebong-ro, Dong-gu, Gwangju 61469, Korea. Tel: 82-62-220-6681, Fax: 82-62-222-4058, E-mail: yhwon@chonnam.ac.kr ORCID: https://orcid.org/0000-0003-4640-4337

This is an Open Access article distributed under the terms of the Creative Commons Attribution Non-Commercial License (http://creativecommons.org/ licenses/by-nc/4.0) which permits unrestricted non-commercial use, distribution, and reproduction in any medium, provided the original work is properly cited.

Copyright (C) The Korean Dermatological Association and The Korean Society for Investigative Dermatology 

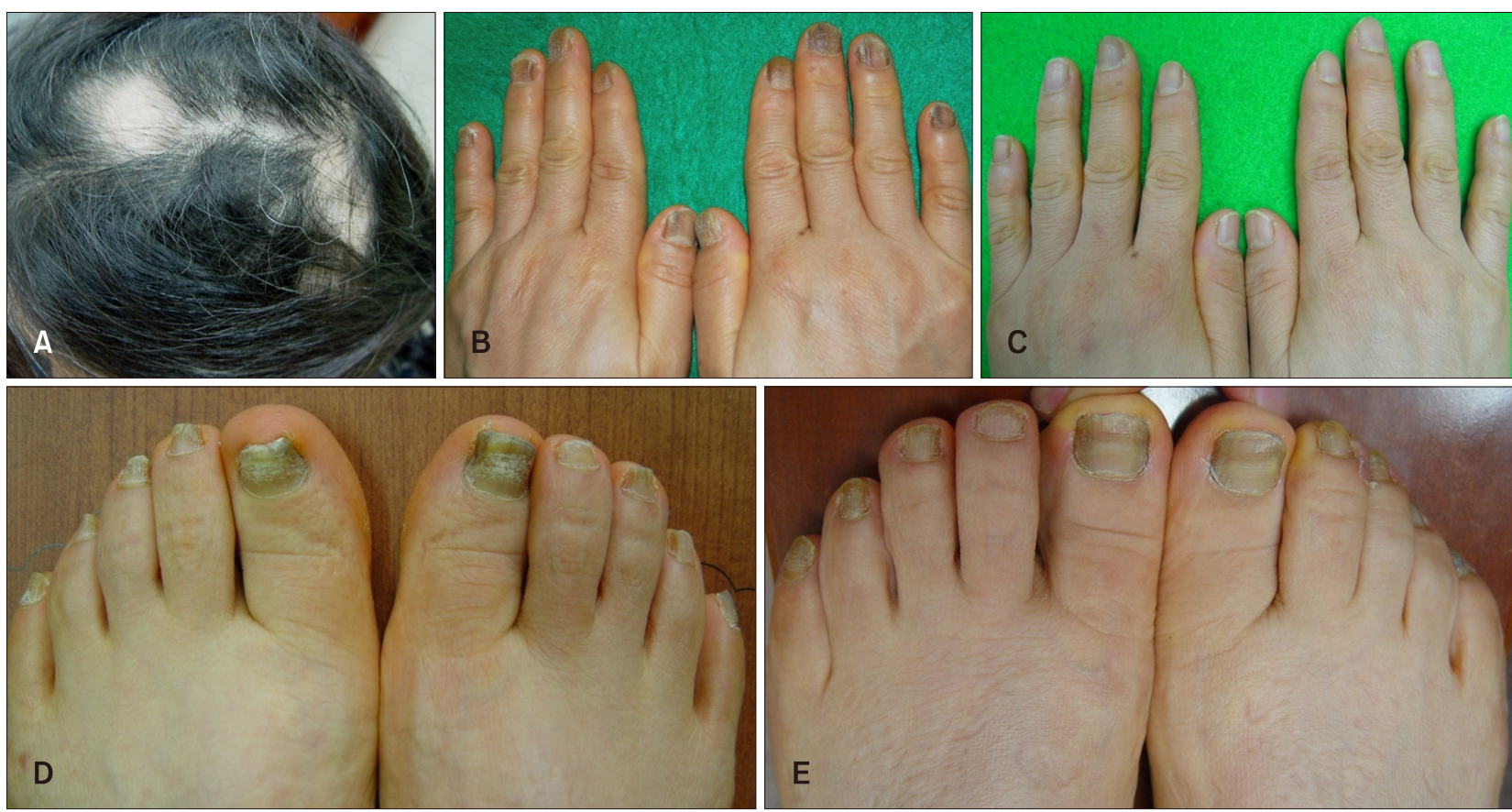

Fig. 1. Clinical features of the patient. Scalp (A) showing oval and round, well-circumscribed patches of hair loss with a smooth surface. Finger and toenails showing various degrees of ridging, lack of luster, subungual hyperkeratosis, and brownish discoloration. Before $(B, D)$ and after $(C, E)$ hydroxychloroquine treatment.
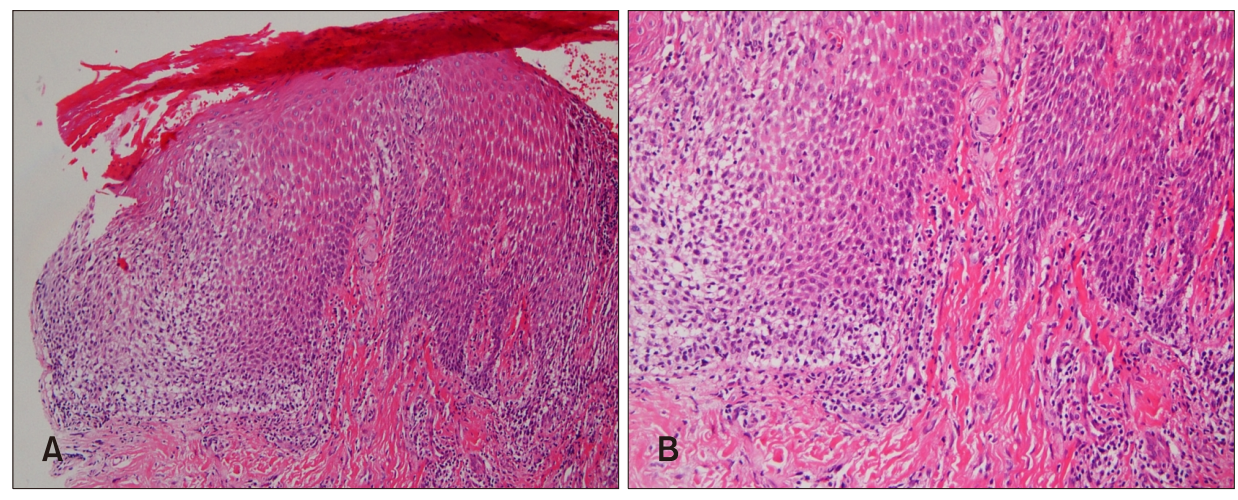

Fig. 2. Histopathologic analysis of skin biopsy performed at the nail matrix revealing hyperkeratosis, acanthosis, mild spongiosis, epidermal lymphoid cells infiltrates, and vacuolar degeneration of the basal keratinocytes (H\&E: A, $\times 100$; B, $\times 200)$. istration of hydroxychloroquine may have interfered with one or more of these pathways in our case. As far as we know, this is the first case of TND treated with hydroxychloroquine in Korean literature. We authors suggest that hydroxychloroquine can be a both effective and safe treatment option for TND.

\section{CONFLICTS OF INTEREST}

The authors have nothing to disclose.

\section{ORCID}

Soo Hyeon Bae, https://orcid.org/0000-0002-3124-3326
Seok Hwan Jang, https://orcid.org/0000-0003-4406-3807 Young Ho Won, https://orcid.org/0000-0003-4640-4337

\section{REFERENCES}

1. Kasumagic-Halilovic E, Prohic A. Nail changes in alopecia areata: frequency and clinical presentation. J Eur Acad Dermatol Venereol 2009;23:240-241.

2. Sehgal VN. Twenty nail dystrophy trachyonychia: an overview. J Dermatol 2007;34:361-366.

3. Ochsendorf FR. Use of antimalarials in dermatology. J Dtsch Dermatol Ges 2010;8:829-844; quiz 845.

4. Xing L, Dai Z, Jabbari A, Cerise JE, Higgins CA, Gong W, et al. Alopecia areata is driven by cytotoxic $\mathrm{T}$ lymphocytes 
and is reversed by JAK inhibition. Nat Med 2014;20:10431049.

5. Alzolibani AA, Rasheed Z, Bin Saif G, Al-Dhubaibi MS, Al
Robaee AA. Altered expression of intracellular Toll-like receptors in peripheral blood mononuclear cells from patients with alopecia areata. BBA Clin 2016;5:134-142.

\title{
Chronic Exfoliative Cheilitis Successfully Treated by Pinhole Method Using $\mathrm{CO}_{2}$ Laser
}

\author{
Chan Seong Park, Ji-Hye Park, Jongeun Lee, Hyun Jeong Byun, Youngkyoung Lim, Jong Hee Lee, \\ Dong-Youn Lee, Joo-Heung Lee, Jun-Mo Yang
}

Department of Dermatology, Samsung Medical Center, Sungkyunkwan University School of Medicine, Seoul, Korea

\section{Dear Editor:}

Exfoliative cheilitis is an uncommon and chronic inflammatory disorder affecting the vermilion of the lips and characterized by continuous peeling of the vermilion and abnormal production of keratin scales ${ }^{1,2}$. Conventional topical treatment is helpful in some cases but it is not that effective in most cases. Invasive treatment such as peeling with laser, cryosurgery and electrocautery is effective in some cases but it can cause severe discomfort ${ }^{1}$.

A 42-year-old male presented with 4 years of history of chronic thick yellowish hyperkeratotic plaques on both lips. The plaques became thicker and were accompanied by pain and oozing (Fig. 1A). He denied lip licking, biting or rubbing habits. The lesion was resistant to conventional topical treatment such as salicylic acid 10\% ointment and vaseline. He complained that his lips kept getting crusts in spite of conventional treatments. In pathologic examination, it showed nonspecific chronic inflammation with interface dermatitis and lymphoplasmacytic infiltration in the upper dermis (Fig. 2). Based on histopathologic findings, we added the process to diagnosis. Although relatively larger numbers of plasma cells are usually present in the mucosal biopsies and may be non-specific, we checked serum antibodies because secondary syphilis can show
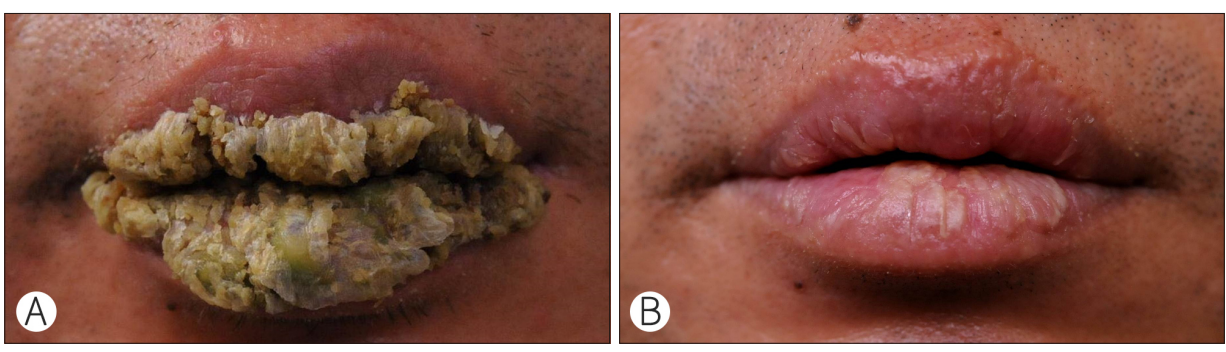

Fig. 1. (A) Highly thick and yellowish plaques on both lips. (B) Almost all of the thick and yellowish hyperkeratotic plaques disappeared after two cycles of treatment. We received the patient's consent form about publishing all photographic materials.

Received April 6, 2018, Revised June 7, 2018, Accepted for publication July 11, 2018

Corresponding author: Ji-Hye Park, Department of Dermatology, Samsung Medical Center, Sungkyunkwan University School of Medicine, 81 Irwon-ro, Gangnam-gu, Seoul 06351, Korea. Tel: 82-2-3410-6578, Fax: 82-2-3410-3869, E-mail: jh1204.park@samsung.com ORCID: https://orcid.org/0000-0002-6699-5202

This is an Open Access article distributed under the terms of the Creative Commons Attribution Non-Commercial License (http://creativecommons.org/ licenses/by-nc/4.0) which permits unrestricted non-commercial use, distribution, and reproduction in any medium, provided the original work is properly cited.

Copyright (C) The Korean Dermatological Association and The Korean Society for Investigative Dermatology 